\title{
FINANCIAL SECTOR EVOLUTION AND COMPETENCIES DEVELOPMENT IN THE CONTEXT OF INFORMATION AND COMMUNICATION TECHNOLOGIES
}

\author{
${ }^{*}$ Ilja Arefjevs ${ }^{1}$, Aivars Spilbergs ${ }^{1}$, Andris Natrins ${ }^{1}$, Atis Verdenhofs ${ }^{2}$, Inese Mavlutova ${ }^{1}$, Tatjana Volkova ${ }^{1}$ \\ ${ }^{1}$ BA School of Business and Finance, Latvia \\ ${ }^{2}$ Riga Technical University, Latvia \\ *Corresponding author's email: ilja.arefjevs@inbox.lv
}

\begin{abstract}
The development of information and communication technologies (ICT) has a significant impact on the business model of companies operating in the financial sector. Digital transformation leads to changing existing business model rapidly, as well as necessity of developing new processes specifically related to the use of ICT in business processes, development of new products and updating existing ones. At present, changes in the demand for ICT related processes in financial sector are observed both through the development of different technologies and their applications core or ancillary processes (e.g. innovations in payment systems including crypto currencies, blockchain-assisted smart contract, credit markets and insurance including peer-to-peer lending). Based on the opportunities offered by ICT, new business models need to be developed in the financial sector to transform these capabilities into new products and services that respond to changing customer demand.

The aim of research to investigate the changes taking place in financial sector in the light of developments in ICT for acquisition of necessary competencies.

Research methodology includes systematic review of scientific literature, analysis of selected financial sector statistics, semi-structured industry expert interviews and statistics analysis.

The empirical study is limited to the financial sector of Latvia. Although due to the global nature of the financial sector the research findings could be applied internationally.
\end{abstract}

Key words: financial sector, fintech companies, ICT, digital competencies, soft skills.

\section{Introduction}

Financial intermediation has changed dramatically over the past 30 years, largely due to technological change arising from advances in telecommunications, information technology, and financial practice (Frame et al., 2018). On the other hand, according to Gregory et al., (2018) banks face increasingly stringent regulatory and complex requirements in order to limit business risks. To comply with these requirements, robust governance and complex ICT infrastructures must be ensured (Gregory et al., 2018). This compliance agenda has never been so topical for Latvia as in recent years. Latvia positioned itself as a potential financial centre for the region, supported by the government order No.126 'On the Financial Sector Development Plan 2017-2019'; however, the amendments of 13 February, 2019 changed this objective to 'develop a stable, secure and internationally competitive financial sector with access to innovative financial services that ensure sustainable growth of the Latvian economy' (On the Financial Sector Development Plan 2017-2019, 2019). Researchers Kotarba (2017), Supe et al., (2019) and others emphasize that digital transformation has influenced changes in the financial sector. Currently, commercial banks are competing with banks for new technology companies, whose products overlap with those offered by banks. With the rapid development of technology, they have also entered the financial services industry, making our lives more comfortable. Arner et al., (2015) consider that 'FinTech' refers to technology enabled financial solutions. Although financial technology companies may not be able to fully utilize banking services in their technology solutions, they still create products where the user is not tied to a particular bank as a customer.

Anagnostopoulos (2017) believes that fintech companies have reached the main channels of commercial banks through technology and innovation in the financial sector. Drasch, Schweizer and Urbach (2018) agree with Anagnostopoulos (that banks are struggling with innovation opportunities, while fintech companies offer technology-enabled capabilities, thus disrupting the value propositions of classical banks). Thakor (2019) suggests that 'Fintech is the use of technology to provide new and improved financial services. Part of the motivation for the emergence of Fintech is that, while information technology has made everything cheaper and more functional, the unit cost of financial intermediation has apparently not changed much in over a century'.

According to Natrins et al., (2019) digital transformation of financial sector is among the most actively researched topics in academic publications in last ten years. According to systematic literature review performed by Verdenhofs, A. \& Tamboveceva, T. in 2018 for successful usage of big data solutions in financial institutions, there should be successful merge of three parties within organization - ICT, analytics and management.

Banks have become both providers of technology as well as users, integrating advanced tools to improve the financial services offered to its clients, both in the corporate and retail business (European banking 
federation, 2018). Technological innovations in the areas of big data, data analysis and mobile devices allow fintech start-ups to support traditional banks with personalized services (Lee \& Shin, 2018). For commercial banks, there is much to learn from how fintech companies are designing the customer proposition and how they are harnessing technology to deliver compelling services (Gulamhuseinwala et al., 2015). The authors agree with Navaretti et al., that in the future the business model of fintech companies, therefore, is highly likely to gradually converge towards that of banks (Navaretti et al., 2017) as there is potential based on experience to ensure brand recognition, expand customer basis through a wide range of product offerings, developing robust digital infrastructure, develop advanced underwriting capabilities, develop risk management experience, extend access to capital and to get license to provide regulated financial services. Giebe concludes that in the era of digitalization one way to manage the organization effectively is to introduce a Chief Digital Officer (CDO) with the central task to execute and implement the change processes (Giebe, 2019).

\section{Materials and Methods}

Authors of the research conducted a systematic review of scientific literature, analysis of selected financial sector statistics as well as performed semistructured industry expert interviews. According to Kelly et al., 2017, the financial institutions have brand/name recognition, large customer base, a wide range of product offerings, comprehensive customer data, robust infrastructure, advanced underwriting capabilities, risk management experience, access to capital, licensed to provide regulated financial services (Kelly et al., 2017).

Fintech company prospects are highly appreciated, and the press presents these companies as 'disruptive', 'revolutionary' that will 'destroy' traditional barriers and financial institutions (World Economic Forum, 2017). According to Mavlutova, I. and Volkova, T. (2019) traditional financial service providers like commercial banks and providers of digital innovations like fintech companies can be described not as competitors but as partners in several aspects. Therefore, in the course of the research hypotheses are stated as follows:

$\mathrm{H}_{1}$ : average growth of operating income of commercial banks outpaced average growth of number of banking branches and customer service units (to be accepted or rejected based on statistics tests).

$\mathrm{H}_{2}$ : growth of both a transaction numbers and volume at terminals with payment cards outpaced the growth of Gross Domestic Product (to be accepted or rejected based on statistics tests).

$\mathrm{H}_{3}$ : soft skills of employees are at least as important as digital skills in the financial sector development in the context of evolution of information and communication technologies (to be accepted or rejected based on a critical assessment of expert interview findings).

The underlying logic of hypotheses was first to test whether there has been an effective shift towards digital channels in the financial sector of Latvia and what kind of implications, if any, on certain competences (i.e. digital skills vs. soft skills of employees) it brings.

Interviewed experts for the purpose of this research

\begin{tabular}{|l|l|l|l|}
\hline Expert \# & \multicolumn{1}{|c|}{ Organisation } & \multicolumn{1}{|c|}{ Position } & \multicolumn{1}{|c|}{ Industry } \\
\hline 1 & AS Swedbank & Head of Digital Innovation and Strategy & Banking \\
\hline 2 & AS SEB banka & Head of Front Channels, Baltics & Banking \\
\hline 3 & AS SEB banka & Innovation Manager & Banking \\
\hline 4 & Citadele Bank AS & Head of E-Business Division & Banking \\
\hline 5 & SEB Global Services Riga & Deputy Head & Shared Services \\
\hline 6 & IPAS Indexo & Chairperson of the Management Board & Asset Management \\
\hline 7 & AAS Balta & $\begin{array}{l}\text { Member of the Management Board, } \\
\text { Technical Director }\end{array}$ & Insurance \\
\hline 8 & AS mogo & Chief Executive Officer & $\begin{array}{l}\text { Car leasing (Financial } \\
\text { Technology) }\end{array}$ \\
\hline 9 & SIA UniCredit Leasing Latvia & Branch Manager & Leasing (conventional) \\
\hline 10 & Robocash Group & Chief Risk Officer & $\begin{array}{l}\text { Consumer lending, marketplace } \\
\text { funding }\end{array}$ \\
\hline 11 & Bigbank AS Latvia Branch & Member of the Management Board & Consumer and business lending \\
\hline 12 & JSC 4finance & Chief Risk Officer & Consumer lending \\
\hline
\end{tabular}


Key objectives of the empirical research are set to be:

1. Study importance of the financial sector of Latvia in the medium term perspective.

2. Study the development of a number of banking branches, operating income as well as a total number and total volume of point-ofsale terminal transactions as well as perform statistics tests.

3. Study importance of digital skills and soft skills of employees working for the financial sector.

4. Study alternatives to acquire and improve certain sets of digital skills of employees demanded by the financial sector.

For the purpose of structured expert interviews on chosen topics, expert candidates have been selected according to the following three criteria - affiliation to an industry of the financial sector, senior or executive management position and industry track record of at least 10 years.

Experts to be interviewed were chosen from the most significant industries so that the combined opinion of all experts would represent the entire financial sector of Latvia. The banking industry prevails since it is the most significant one within the financial sector. Since the banking sector of Latvia and Baltics is largely dominated by Nordic companies (Arefjevs, 2017), four experts from largest financial groups were included in the list. Consumer lending is also widely presented since this is a fast growing industry, which is expanding abroad too. Expert interviews were conducted in the time period from December 2019 till February 2020.

The average interview lasted one hour and was conducted either in person or over phone. The interview language was either English or Latvian. After the interview a condensed summary of expert answers was drafted in English and delivered to the interviewed expert for proofreading. Therefore, expert interview findings presented in the research in a concentrated manner in English have been proofread by experts.

\section{Results and Discussion}

The financial sector of Latvia changed its operating model substantially after a major crisis in 2008-2009. On the one hand, cutting down banking branch networks was triggered by a need of implementing strict cost saving measures. On the other hand, rapidly developing digital technologies and high adoption rates among banking customers clearly facilitates the process of a shift from face-to-face channels to a remote service mode. In particular, the Figure 1 illustrates an obvious downtrend of number of banking branches and customer service units (B\&CSU) from 2010 to 2018. The total operating income of banks, largely reflecting commissions and fees collected in branches in the past, does not show signs of sustainable decline.

Further, the authors checked the difference between average trends in numbers of banking branches, customer service units and operating income of commercial banks during 2010-2018. The following hypotheses were tested: operating income of commercial banks during 2010-2018 is growing faster than numbers of banking branches, customer service units of commercial banks. For these statistics tests the hypotheses were designed as follows:

$$
\begin{aligned}
& H_{1(0)}: \mu_{O I}-\mu_{B C S U} \leq 0 \\
& H_{1(A)}: \mu_{O I}-\mu_{B C S U}>0
\end{aligned}
$$

where: $\mu_{O I}$ - average growth of operating income of commercial banks during 2011-2018, \% to 2010,

$\mu_{B C S U}$ - average growth of number of banking branches and customer service units of commercial banks during 2011-2018, \% to 2010 .

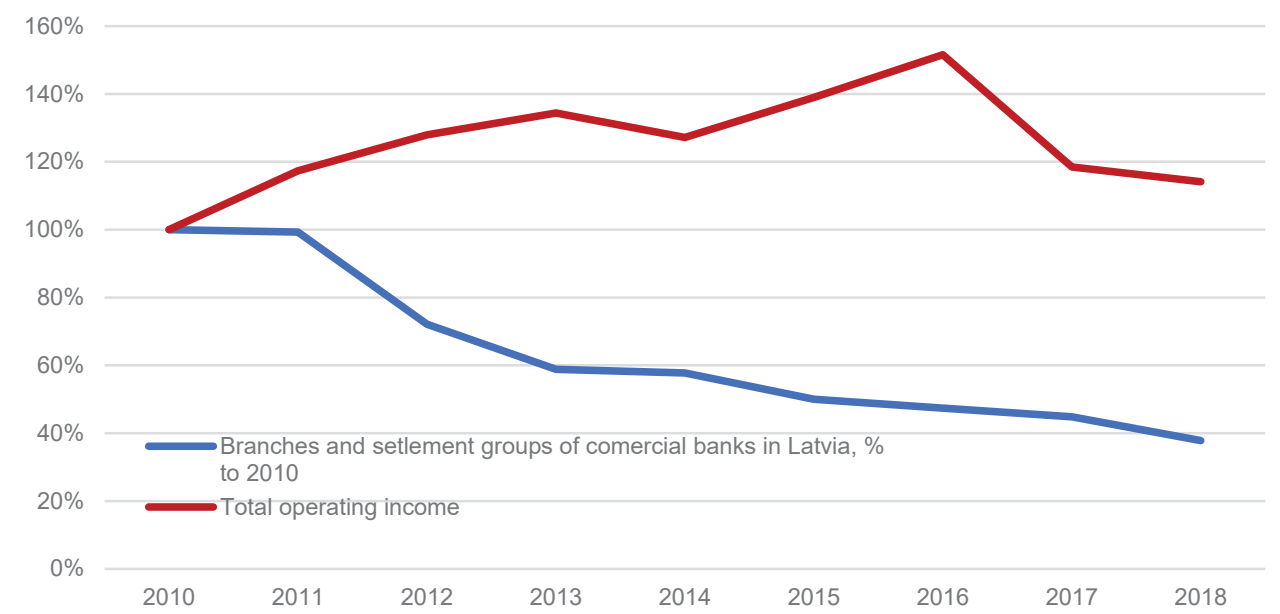

Figure 1. Branches, CSU and operating income of commercial bank trends, \% to 2010.

Source: compiled by authors based on FCMC data. 


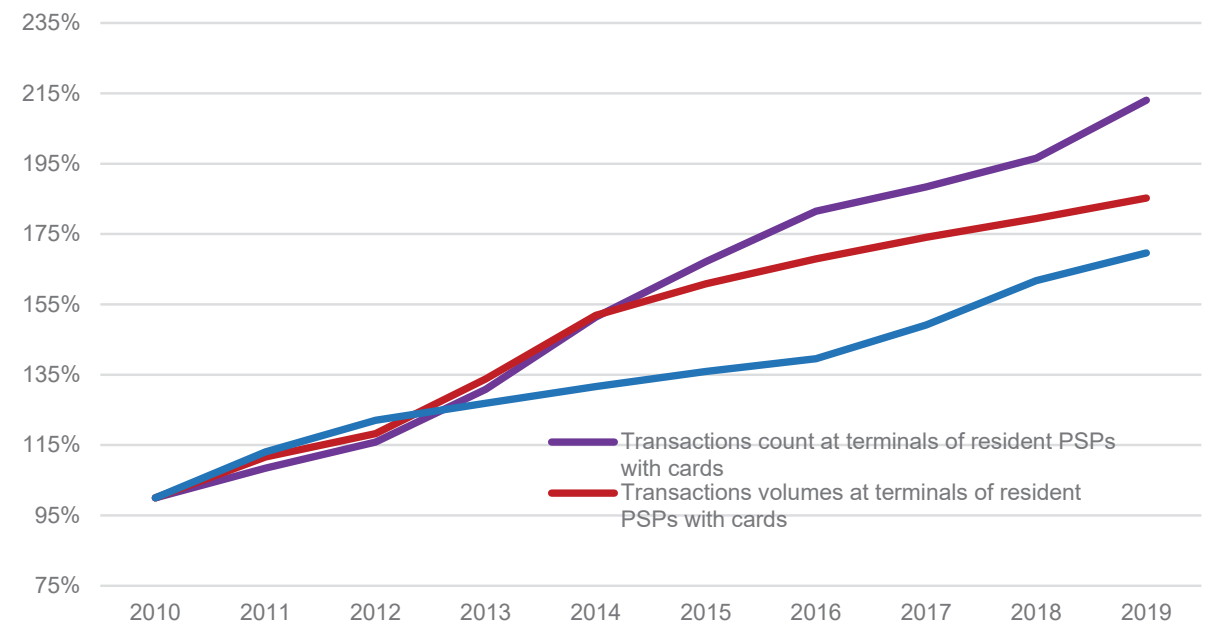

Figure 3. Transaction numbers and volumes at terminals with cards and GDP trends, \% to 2010.

Source: compiled by authors based on BoL and CSB data.

Based on FCMC data (FCMC, 2020) and using the Students's $t$-test with a critical value $=0.05$, the authors computed Student's $t$-statistic (7.8315), compared it with critical value (1.8946) and rejected null hypothesis. It can be concluded from this hypothesis testing that there is strong evidence that operating income of commercial banks is growing faster than numbers of banking branches and customer service units. This conclusion is supported with very low p-values $(p=0.00005)$.

Additionally, both the total number of transactions as well as the total volume of transactions made in the point-of-sale terminals demonstrated stable growth trends, as shown in the Figure 3. It is noteworthy that the total number of transactions grew twice as fast as the total transaction volume clearly pointing to the fact of a declining value of an average transaction volume, which is generally a very typical pattern when some service is being widely adopted.

Further, the authors checked the difference between average trends in numbers and volumes of transactions at terminals of resident PSPs with cards and GDP growth during 2010-2019. The following hypotheses were tested: both, numbers and volumes of transactions at terminals of resident PSPs with cards during 2010-2019 is growing faster than GDP. For this research, the hypotheses were designed as follows:

Based on Bank of Latvia (BoL, 2020) and CSB (CSB, 2020) data and using the Students's $t$-test with a critical value $\alpha=0.05$, the authors computed Student's $t$-statistics (3.3735 vs 3.7921), compared it with critical value (1.8595) and rejected both null hypothesis.

It can be concluded from this hypothesis testing that there is strong evidence that both, numbers and volumes of transactions at terminals of resident PSPs with cards are growing faster than GDP. This conclusion is supported with very low $\mathrm{p}$-values $(p=$ 0.0049 vs 0.0026 respectively).

Proceeding with expert interview findings, the first question was defined as How do you see importance of

\section{Null and alternative hypothesis statements for transactions numbers and volumes at terminals with cards and GDP trends}

\begin{tabular}{|c|c|c|}
\hline Hypothesis type & GDP vs transactions numbers & GDP vs transactions volumes \\
\hline$H_{2(0)}:$ & $\mu_{T N}-\mu_{G D P} \leq 0$ & $\mu_{T V}-\mu_{G D P} \leq 0$ \\
\hline$H_{2(A)}:$ & $\mu_{T N}-\mu_{G D P}>0$ & $\mu_{T V}-\mu_{G D P}>0$ \\
\hline
\end{tabular}

where: $\mu_{G D P}$ - average GDP growth during 2011-2019, \% to 2010;

$\mu_{T N}-$ average growth of transaction numbers at terminals of resident PSPs with cards during 2011-2019, \% to 2010

$\mu_{T V}-$ average growth of transaction volumes at terminals of resident PSPs with cards during 2011-2019, \% to 2010 . 
the financial sector for the economy in Latvia now and in the nearest future?

The condensed summary of expert answers suggests that the financial sector is very significant for the economy and can be considered to be its backbone. There are reasons to believe that the financial sector is becoming increasingly critical for the economy due to rapid digitalisation (i.e. role of cash is decreasing, transactions are performed mostly digitally via intermediation of the financial sector). In general, the financial environment in Latvia can be considered to be very stable (i.e. taking the financial sector and the monetary system in a broad way). In future, further growth is expected. Faster transactions will facilitate consumption and thus economy in general. A number of transactions is poised to jump substantially. Services will become highly available due to technologies. User experience will become increasingly important.

Latvia-based financial technology companies are successfully expanding their operations outside Latvia, thus to some extent compensating a negative impact caused by shrinking the so-called non-resident sector.

Anti money laundering matters are clearly in the focus and potentially might be exaggerated at the moment both in Latvia and other Baltic countries (i.e. Estonia, Lithuania). Thus, negative consequences are expected to persist in the nearest future. On the other hand, importance of the financial sector increased due to new functions in relation to sanction screening and transaction monitoring.

The second question was forward looking and phrased in the following way: How would you briefly describe future of the financial sector in five years from now and longer?

a. Products and services:

Experts responded that traditional products and services are generally expected to stay. However, more automation (and less human involvement) as well as other technology advances are clearly expected - more precise customer profiling, clear shift from physical branched to online operations, real time analysis and transaction execution, smooth and simple processes. Biometrical parameters will be in use increasingly more often. A shift from using mobile phones to chats and bots is already taking place. Employees released from simple jobs will solve more complicated customer cases.

Products and services will become less visible. There will be increasingly less need for customers to go after a product or service. Rather products and services will reach customers when they need it. Different customer behaviour is expected depending on a customer generation though. Younger generations will be more open to technology advances like certain virtual services (e.g., robo-advisory, self-services).
Customer insights will add more value to offering right products to right customers. Other researchers (eg., Vives, 2018) also believe that new digital technologies automate potentially may provide new and more costeffective products in parts of the financial sector, ranging from lending to asset management, portfolio advice and the payment system.

More harmonisation across regions expected. Further product and process simplification is expected to take place. Thus, financial products and services will be easier to understand and to use by the general public. There will be some exceptions though. For instance, business-to-business products will still be tailor-made to a large extent. On the other hand, underserved segments like small and medium enterprises will get more attention via simplified and accessible offering, thus being able to develop faster than the financial sector in general.

b. Local vs international vs global

Experts believe that financial services provision borders are expected to disappear. Already now financial products are being developed globally (e.g., wide insurance coverage etc.). Globalisation of certain services already takes place, especially for digital providers, to whom a customer residence is not important from an operational point of view. Thus, a geographical expansion is possible in case of very focused attractive products and services (eg. Revolut, N26). Thus, a potential strategy for small and agile market players is clearly present. More cross-border business, more disruptive approaches will emerge. Global technology providers have huge chances to win the race. Eventually the race between big technology companies and major central banks may arise. Legal and regulatory constraints are important though, and they are expected to stay for a longer term than five years.

Combined offering is already available (e.g., when booking a car, insurance and other services offered at the same time). Demand for local products and services can emerge due to a patriotic perspective. Emotional affirmation is still considered to be important. Therefore, there is space for localised solutions. In some cases a scale is important, in some case a local 'touch' will be appreciated. Cost efficient solutions for specific markets are possible too. Digital product offering was names as a precondition for expansion. All in all, either a scale or a uniqueness advantage can be a precondition to succeed.

The biggest tug of war is expected between local and global. Latvia faces the risk to lag behind the developed world. One reason is a smaller language in terms of a number of people using it; another is population living outside urban areas.

Authors emphasise that according to the Digital Banking report 2019 Retail banking trends and 
predictions based on the survey for the first time ever among strategic priorities for 2019 (Marous, 2017), the use of big data, artificial intelligence and advanced analytics was ranked first, outpacing improving the customer experience as the number one trend for the previous years. Consequently, financial sector managers need to provide pro-active and effective competence-based management to ensure that the proper competencies are in place for achieving the business development goals and demonstrate high business performance in both short and long term. On the other hand, according to the report 'Skills and competences in the Nordic financial sector' (2019), social and adaptability skills are generally ranked higher that hard skills such as digital skills, for example, which are one of the most required hard skills. Therefore, experts have been asked to reflect on this finding in order to test $\mathrm{H}_{3}$ : soft skills of employees are at least as important as digital skills in the financial sector development in the context of evolution of information and communication technologies.

According to the experts interviewed within the research, soft skills are somewhat more important than specific hard skills (i.e. digital skills). However, the gap is estimated to be very small. A combination of soft and hard skills is important. It was concluded that Latvia may be lacking people with hard skills in general.

Soft skills have to be continuously developed starting from the early childhood (and furthermore within organisations via internal culture). Culture diversity is one of facilitators of soft skill development. Mentorship programmes can be considered to be an effective tool to strengthen soft skills. Hard skills development can be subject to specific educational and training programmes. Problem solving and analytical skills are becoming increasingly important hard skills in the light of big data and artificial intelligence.

Delivering user experience is pivotal in the digital era. User experience comprises a function of hard and soft skills (via empathy). This is also indirectly confirmed by Chen L., Danbolt J., Holland J., 2014, who state that the way banks learn to use their intangible and tangible assets, including the competencies of managers and professionals, to create an attractive, customer-oriented service will play an important role in this competition. General digital user skills are likely to be considered to be 'default' skills in the nearest future, setting an expectation that nearly all employees should possess those. Specific competences related to big data, machine learning and robotics have to be empowered by appropriate educational programmes (i.e. higher schools and universities). Thus, on the basis of the received expert opinion, authors accept the third hypothesis stating that soft skills of employees are at least as important as digital skills in the financial sector evolution.
The authors revisited the Nordic research (2019) again to obtain expert opinions on the statement that data analysis and related skills are most likely to be maintained in-house while programming and ICT have the highest score for outsourcing and consultants. Expert interviews suggest that for each company it is important to define core competencies and develop and maintain those in-house. Other competencies can be outsourced. A specific decision is to a large extent dependent on a business model while having critical mass is a precondition for inhouse competences. In particular, data analysis, maths and big data can form a core competence, which is a critical success factor for a competitive advantage, thus kept in-house. Additionally, data visualisation skills are required.

To sum up the results and discussion section, the key findings are:

1. The financial sector is very significant or even critical to the whole economy. It is expected to keep its major role in future while borders of financial services provision will disappear due to technological advancements and competition.

2. The financial sector experienced a significant shift in customer service channels from face-to-face to remote channels.

3. Soft skills of employees are found to be at least as important as digital skills in the financial sector development in the context of evolution of information and communication technologies.

4. The answer to the question about outsourcing of certain competencies (like ICT and engineering) is directly linked to core competencies of a company. Keeping analytical and-problem solving competences in-house can be considered to be a common approach in the financial sector.

\section{Conclusions}

Data, capabilities of using data, data analytics and understanding of the importance of data at the strategic level are both essential factors and catalysts for the future development of the financial sector. These factors will have a major impact on the competitiveness of both financial technology companies and banks.

The financial sector is becoming increasingly critical for the economy due to rapid digitalisation. Faster transactions will facilitate consumption and thus economy in general. A number of transactions is poised to jump substantially. Services will become highly available due to technologies. User experience is expected to become increasingly important.

Latvia-based financial technology companies are successfully expanding their operations outside Latvia compensating for a negative impact caused by shrinking the non-resident banking segment. 
Current development of the financial sector poses challenges from a competence management perspective to both traditional players as well as financial technology companies. Digital competences are assessed to be important; however, soft skills like social skills and adaptability ranked somewhat higher. Digital skills as well as specific big data, machine learning and robotics related skills are suggested to be acquired mainly via educational programmes while soft skills have to be mainly acquired by people themselves throughout life starting from early childhood. General preference for in-house competences are for data analysis and problem solving while hard ICT competences are more likely to be outsourced. A decision on what competences to be kept in-house and which should be outsourced is to be taken based on considerations about core competences of a particular company, critical mass for competence maintenance and other factors.

\section{Acknowledgment}

The research was supported by the BA School of Business and Finance Internal Grant Research Project 'The Assessment of Competence Management in the Latvian Financial Sector'.

\section{References}

Anagnostopoulos, I. (2018). Fintech and regtech: Impact on regulators and banks. Journal of Economics and Business, 100, 7-25.

Arefjevs, I. (2017). Efficiency Assessment Concept Model for Financial Alliances: Bank assurance in Baltic Pension Fund Management. European Integration Studies, 11, 186-198.

Arner, D. (2015). The evolution of fintech: a new Post-Crisis paradigm? Retrieved February 10, 2020, from http://www.juliaocoelho.com/wp-content/uploads/2019/05/SSRN-id2676553.pdf.

Bank of Latvia. (2020). Payment statistics. Retrieved February 10, 2020, from https://www.bank.lv/en/statistics/ stat-data/payment-systems-statistics.

Central Statistical Bureau of Latvia. (2020). Gross domestic product. Retrieved February 10, 2020, from https:// www.csb.gov.lv/en/statistics/statistics-by-theme/economy/gdp.

Chen, L., Danbolt, J., \& Holland, J. (2014). Rethinking bank business models: the role of intangibles. Accounting, Auditing \& Accountability Journal.

Drasch, B.J., Schweizer, A., \& Urbach, N. (2018). Integrating the 'Troublemakers': A taxonomy for cooperation between banks and fintechs. Journal of Economics and Business, 100, 26-42.

Finance Finland, Finance Norway, FA Denmark. (2019). Skills and competences in the Nordic financial sector. Retrieved January 5, 2020, from https:/www.finansnorge.no/contentassets/ b16acd7f75ed4442ae2a83f284cf84ab/fellesnordisk-kompetansekartlegging-2019/nordic-competenceand-skills-report-2019.pdf.

Financial and Capital Market Commission. (2020). Statistics. Retrieved February 10, 2020, from https://www. fktk.lv/en/statistics/.

Frame, W.S., Wall, L.D., \& White, L.J. (2018). Technological change and financial innovation in banking: some implications for fintech.

Giebe, C. (2019). The Chief Digital Officer-Savior for the Digitalization in German Banks? Journal of Economic Development, Environment and People, 8(3), 6.

Gregory, R.W., Kaganer, E., Henfridsson, O., \& Ruch, T.J. (2018). IT Consumerization and the Transformation of IT Governance. Mis Quarterly, 42(4), 1225-1253.

Gulamhuseinwala, I., Bull, T., \& Lewis, S. (2015). FinTech is gaining traction and young, high-income users are the early adopters. Journal of Financial Perspectives, 3(3), 16-23.

Harzallah, M., Berio, G., \& Vernadat, F. (2005). Analysis and modelling of individual competencies: toward better management of human resources. IEEE Transactions on systems, man, and cybernetics-part A: systems and humans, 36(1), 187-207.

Kelly, S., Ferenzy, D., \& McGrath, A. (2017). How financial institutions and fintechs are partnering for inclusion: Lessons from the frontlines. Center for Financial Inclusion at Accion

Kotarba, M. (2016). New factors inducing changes in the retail banking customer relationship management (CRM) and their exploration by the FinTech industry. Foundations of management, 8(1), 69-78.

Lee, I., \& Shin, Y.J. (2018). Fintech: Ecosystem, business models, investment decisions, and challenges. Business Horizons, 61(1), 35-46.

Marous, J. (2017). Retail Banking Trends and Predictions 2019. LLC Issue, (260).

Mavlutova, I., \& Volkova, T. (2019, October). Digital Transformation of Financial Sector and Challengies for Competencies Development. In $20197^{\text {th }}$ International Conference on Modeling, Development and Strategic Management of Economic System (MDSMES 2019). Atlantis Press. 
Medina, R., \& Medina, A. (2015). The competence loop: Competence management in knowledge-intensive, project-intensive organizations. International Journal of Managing Projects in Business.

Mulder, M. (2011). The concept of competence: blessing or curse? In Innovations for competence management. Conference proceedings (pp. 11-24).

Natrins, A., Supe, L., Mikelsone, E., \& Sarnovics, A. (2019). Information Technology Competency Management in the Financial Sector in Latvia. In Proceedings of the $12^{\text {th }}$ International Scientific and Practical Conference. Volume II (Vol. 98, p. 103).

Navaretti, G.B., Calzolari, G., Mansilla-Fernandez, J.M., \& Pozzolo, A.F. (2018). Fintech and Banking. Friends or Foes? Friends or Foes.

Supe, L., Nātriņ̌̌, A., Miķelsone, E., \& Sarnovičs, A. (2019). Information Technology Competency Management in Financial Sector: Literature Review. Rural Development 2019, 2, 268.

Thakor, A.V. (2019). Fintech and banking: What do we know? Journal of Financial Intermediation, 100833.

Verdenhofs, A., \& Tambovceva, T. (2018, May). Big Data and Associated Skills: Systematic overview. In Economic Science for Rural Development Conference Proceedings (No. 49).

Vives, X. (2019). Competition and stability in modern banking: A post-crisis perspective. International Journal of Industrial Organization, 64, 55-69.

White, R.W. (1959). Motivation reconsidered: The concept of competence. Psychological review, 66(5), 297.

Wieczorek-Szymańska, A. (2015). Employees' Competencies Management in Bank Sector. Reports on Economics and Finance 1(1), 105-113. 